\title{
28 Research Square \\ Conflicts and Ethical Dilemmas in Times of the Covid 19 Pandemic
}

AGUEDA MUÑOZ DEL CARPIO TOIA ( $\square$ teamproyectosganadores@gmail.com )

Universidad Catolica de Santa Maria de Arequipa https://orcid.org/0000-0003-0501-7314

Emanuele Valenti

Instituto de Ética Clínica Francisco Vallés

Fernando Torres

Universidad de Buenos Aires

Luis Manuel López Dávila

Universidad de San Carlos de Guatemala Facultad de Ciencias Médicas: Universidad de San Carlos de

Guatemala Facultad de Ciencias Medicas

Lucia Begazo Muñoz del Carpio

Universidad Catolica de Santa Maria de Arequipa

Enrique Mendoza Carrera

Academia Nacional Mexicana de Bioética

\section{Research Article}

Keywords: Pandemic, COVID-19, conflicts, ethical dilemmas, health services

Posted Date: February 22nd, 2022

DOI: https://doi.org/10.21203/rs.3.rs-1370307/v1

License: (c) (1) This work is licensed under a Creative Commons Attribution 4.0 International License.

Read Full License 


\section{Abstract}

Background: Throughout the Pandemic caused by COVID-19, health professionals have faced the fight against this disease in the front line, even without effective treatment, this uncertainty led to the presentation of various ethical crises in health services to be analyzed.

Methods: An exploratory, cross-sectional investigation was developed, for which a self-application instrument was designed, in the online interview modality, aimed at doctors and university professors involved with bioethics with the purpose of analyzing ethical aspects in care of COVID-19 patients.

Results: 100 interviews were collected for the convenience of their work location, $67 \%$ worked in hospitals, $11 \%$ in clinics, and $22 \%$ in universities teaching the bioethics course. Problematic situations related to high exposure to risks of health professionals, infrastructure gap, ICU beds, and hospital beds were identified as problematic situations. The main conflicts and ethical dilemmas were related to decisionmaking for the allocation of resources, lack of culture of self-care for the health of the population, the risk of contagion from the doctor, therapies not supported by clinical trials, and patient-physician prioritization.

Conclusions: It was evidenced that university doctors and teachers identified various problematic situations, conflicts and ethical dilemmas in the care of COVID-19 patients, which compromise ethical values of maximization of benefits, equity, in addition to ethical principles such as beneficence, justice, reciprocity, solidarity, integrity, respect, vulnerability, dignity, damaging their human and legal rights.

\section{Background}

In December 2019, in Wuhan China, the first cases of easily transmitted atypical pneumonia [1] were presented, which, shortly after, was attributed to the SARS-CoV-2 virus [2]. The World Health Organization, faced with the rapid advance of the new disease at a global level, declared the COVID-19 Pandemic in March 2020 [3] and since then, health services have faced this unprecedented health crisis, with a high demand for patients in critical condition, in the midst of large gaps and deficiencies in the pre-existing health systems of the pandemic, to date, more than eighty-five million infected and more than one million eight hundred deaths have been reported [4] worldwide.

In this health emergency, the health services have shown their strengths and weaknesses, in the face of the massive need for beds, medicines, personal protective equipment and, above all, the lack of specialized professionals for the care of seriously ill patients [5], generating various ethical tensions, due to the urgent need to promote equality in patient care and equity in the distribution of resources in health services without any distinction. However, in this situation, health resources became insufficient even in countries with solid health systems, with the consequent collapse of public hospitals and private clinics, causing demands for maximum performance of the health professional in emergency conditions, with scarce resources and risk of contagion and death of the health personnel themselves [6-7]. 
The World Health Organization (WHO), aware of the need to achieve equity in patient care, urged governments to make decisions to implement measures that ensure the reduction of the transmission of COVID-19 in the population, but also measures and policies to alleviate the impacts at the health systems, social and economic level [8], it is in this new scenario, which has revealed, the great vulnerabilities of the population and of the institutions.

In the management of this pandemic health crisis, ethical guidelines and recommendations stand out under which previous pandemics have been managed, especially for triage of critically ill patients, assignment of mechanical ventilators [9-10] and protection of the most vulnerable. It is worth analyzing whether these recommendations from past pandemics are sufficient to face the new ethical dilemmas of this pandemic, unprecedented due to the rapid expansion at the global level, the high rates of contagion and mortality, with no cure to date, generalized inability of health care systems, health care for the excessive demand of patients [11] reinfection and second waves of massive infections [12]. It should be remembered that an ethical dilemma in health occurs "when a situation in the medical practice involves an operational conflict between two (or more) ethical imperatives, where applying one may mean transgressing the other, we are facing an ethical dilemma" [13-14]. Among the basic ethical recommendations for the management of pandemics we find: "to maximize the benefits produced by scarce resources, treat people equally, promote and reward instrumental value and give priority to the most disadvantaged" [15-16]. Likewise, various ethical recommendations have been given for the admission and discharge of patients in the Intensive Care Unit (ICU) in exceptional circumstances, when the health services have limited resources, among other important documents in force in any pandemic, however, we need to know if the ethical dilemmas that have arisen in all these months of the pandemic could be analyzed or adapted from these recommendations.

Assistance in a pandemic context implies facing a greater and urgent demand, which always exceeds the possibilities, both in infrastructure and in materials and trained human resources, these situations would cause various conflicts between health personnel and patients, who must be attended with diligence and under proper distributive justice.

For all these reasons, the study was proposed, which aimed to explore the conflicts and ethical dilemmas identified in the time of care of COVID 19 patients and propose an ethical analysis based on the findings.

\section{Methods}

\section{Participants and Design}

It is a descriptive exploratory study, which was carried out in the period between August and September, 2020 in Peru. The selection of the sample was intentional, consecutive and consisted of 100 people, who consented to participate anonymously, confidentially and voluntarily. Participants received a direct invitation via online. The questionnaire was developed for this study and the length of time that remained open the form of the online interview, closed when managed to make the sample size. The sample took 
into account criteria such as: geographical distribution, gender, age, scientific discipline, field of work, specific area of professional work, areas of dominance and institutional affiliation, among others. The basic criterion has been that of significance, taking into account, in addition, a criterion of heterogeneity with respect to the choice of the people summoned to offer their opinion.

Doctors who were directly treating patients with COVID 19 infection in Trauma shock, hospitalization, Peruvian Intensive Care Units (ICUs), and local and international university professors of bioethics were invited. It was decided to include these two groups, considering that the field information of doctors who work on the front line and face conflicts and dilemmas is important, but also that of university bioethics teachers, who have the task of training the professional and developing competencies that allow them to identify conflicts and ethical dilemmas in professional practice, incorporating ethics, "philosophy and Social Sciences in deliberation and decision-making processes" [17].

\section{Variables}

The variables studied were: Age (years), gender (male, female, other), workplace (ICU, emergency, hospitalization of medicine, triage, university professors of bioethics), contact with patients and place of contact with COVID 19 patients, situations that arise in the health system and conflicts and ethical dilemmas that occur in times of pandemic.

\section{Statistical analysis}

For data analysis, the statistical program IBM SPSS version 26 was used. To describe the quantitative variables, the distribution of frequencies and averages were used.

\section{Ethical analysis}

In the findings, the ethical problems and conflicts that were raised by the interviewees were identified and later the moral values that come into tension and that form the ethical dilemma were contrasted by spinning the contextual arguments and ethical reflection based on ethical principles and discussion of the results with experts in bioethics in the region.

\section{LIMITATIONS}

The data was collected by Google Forms and responses were only accepted until reaching 100 questionnaires, so we could have some selection bias, however, the results could be useful for new studies.

\section{Results}

The sample consisted of 100 participants, in terms of gender, $59 \%$ were women and $41 \%$ men, the average age of the respondents was $40.19 \pm 11.1$ years. 
Regarding the workplace, $67 \%$ worked in hospitals, $11 \%$ in clinics and $22 \%$ in universities teaching the bioethics course (see table 1).

The situations that occur most frequently in the health system in the COVID 19 pandemic are high exposure to risks from health professionals, lack of human resources, lack of personal protective equipment, exposure to high viral load, discrimination and mistreatment of doctors, little national research on COVID19, infrastructure gap, lack of ICU beds and hospital beds (see table 2).

The interviewees identified as very frequent or frequent the ethical dilemmas related to conflicts in the triage of patients and the availability of beds, in saving the greatest number of lives and collapsed health services, the conflict between the effort of doctors to care for patients and the lack of a culture of selfcare for the health of the population, the conflict of values between the duties of the doctor to save life and the risk of life of the doctor himself due to the lack of adequate personal protective equipment and environmental work conditions, conflicts between the specialty of the doctor and the functions he exercises in the context of a pandemic in patient care (see Table 3).

\section{Discussion}

Ethical issues are inexorably present in all phases of a pandemic and in situations of disasters and catastrophes, hence the importance of developing studies on this unprecedented health emergency due to its magnitude and rapid global expansion. The present study was developed to identify the perception of the main ethical dilemmas and situations that arise in the care of COVID 19 patients.

Among the most frequent problematic situations in health services, those that directly affected health professionals were identified as high exposure to occupational risks, lack of personal protective equipment (PPE), exposure to high viral load and lack of wage payments. Occupational exposure added to lack of services could be a fatal combination for health professionals who serve on the front line, since it has been demonstrated a greater risk of transmission in personnel during their exposure to aerosols [16] of patients hospitalized for COVID 19 [19], hence the importance of minimizing contagions [20] and

providing sufficient PPE and of adequate quality to ensure less exposure ${ }_{(21)}$, since poor quality PPE could give false security to health personnel with the consequent contagion and death [22].

The results of the study showed that the doctors had had, throughout this health emergency, episodes of discrimination and abuse. These results are similar to those found in various studies on attacks on health personnel before the pandemic [23] and under the context of the pandemic [24], as well as discrimination and stigmatization, which in some cases materializes in workplace violence due to the panic of the general population at contagion by health personnel [25], this situation being a violation of human rights under the defense of human rights, with serious repercussions on the mental and emotional health of the victims [26]. It has been observed that health personnel in critical and non-critical areas suffer from burnout [27-28], stress [29], anxiety and depression [30]. 
The results also showed problematic situations related to the deficiencies of the health system such as health infrastructure gaps, lack of specialized human resources to care for patients in critical condition, little attention to public health, among others, this situation reflects severe problems in the social determinants of health and health inequities, especially in rural regions, poverty areas, jungle regions and provinces far from large cities, where levels of inequity and social injustice are evident, as pointed out by Withers, Mellissa [31].

Governments in pandemic made decisions such as social isolation, protection of vulnerable persons and widespread use of masks, to mitigate the spread while preparing health services for care hospital mass of patients many critics, however on this path full of urgent needs, they neglected primary health care, with public health in charge of ensuring the common good, eliminating inequities, preventing neglect of other diseases, and promoting social justice.

In our results, we also evidenced a perception of little research in Peru on COVID-19, in the face of a context of great and multiple uncertainties that require urgent responses through research, such as the lack of effective treatment and a vaccine, ignorance the extent and duration of natural immunity after a SARS-CoV-2 infection, as well as the reasons for higher mortality in ethnic minorities [32] lack of effectiveness in containment campaigns and self-care of health, need for access to molecular tests and medical devices, as well as other problems that have increased the vulnerability [33] of people, such as the greater frequency of mental health problems, family violence, change in educational systems, loss of employment, poverty and many others that may require evidence-based responses through collaborative national research. However, it is imperative that, in the context of the pandemic, quality research is generated that guides decision-making based on scientific evidence and with the use of data under a framework of human rights and ethical principles [34]; Therefore, it is necessary for the Research Ethics Committees, despite the accelerated review times, to be attentive to any attempt to exploit vulnerable groups or exploitation of their data (Sorokin et al. 2020), exposure to inappropriate risks, breach of the confidentiality of patient data, they must analyze the ethical justification, scientific validity and social value of each research protocol on COVID-19, no relaxation of ethical or scientific criteria can be admitted and even more if it is about trials with vaccines against this fearsome disease [35]

On the other hand, our results suggest that several of the problematic situations are related to public health, the management and allocation of resources, which should be analyzed with values such as solidarity, reciprocity, well-being, social justice and equity; using these approaches, we can achieve achievements for society as a whole, without individualistic positions [19], as established in the Universal Declaration of Bioethics and Human Rights of UNESCO (2005): "the fundamental equality of all people must be respected human beings in dignity and rights, in such a way that they are treated with justice and equity " [36].

In the study, various conflicts and ethical dilemmas were identified under the context of COVID 19, such as those related to the efforts and great difficulties to maximize the benefits of the care of these patients, compared to health services with scarce resources; These situations forced immediate decision-making 
that involved ethical principles related to: seeking the greatest good for the greatest number of patients (utilitarianism), the allocation of ventilators based on the patient's need [37] (equality, solidarity, justice ), protection and respect for the patient's will to accept or reject invasive treatment (autonomy, freedom) and in some cases decisions were made to prioritize patients according to social benefit.

The interviewees identified as frequent conflicts and dilemmas: conflict between the effort of doctors to care for patients and the lack of culture of self-care of the population's health, conflict of values between the doctor's duties to save life and the risk of life the doctor himself due to lack of adequate personal protective equipment and work environment conditions, conflicts between the doctor's specialty and the functions he performs, dilemmas about prioritizing the allocation of scarce resources, conflict between the treatment plan and the information without scientific support or therapies not yet proven with clinical trials mainly.

Next, some of these conflicts and ethical dilemmas are analyzed based on ethical values of profit maximization, equal treatment, as well as ethical principles such as beneficence, justice, reciprocity and solidarity.

\section{Decision-making to prioritize patients in their care and life support measures in the ICU:}

The Pan American Health Organization (PAHO) has also added ethical guidelines for this pandemic for "the use of limited resources in critical health services [38], recommending prioritization with transparent criteria to generate trust in the population and decrease burdens on health professionals, it also recommends saving the greatest number of lives, prioritizing patients with better clinical conditions to survive treatment in addition to palliative care for those who do not access treatment, as well as treating people fairly [34].

Robert, René 2020, in an article referring to ethical dilemmas in intensive care units, recognizes that various ethical questions arise when intensive care physicians must make painful decisions contrary to their basic ethical principles in the face of the high demand of patients in services without immediate availability of beds [39].

Decisions in the context of the pandemic have been difficult and unavoidable, both in the prioritization of patients to be hospitalized in ICU beds, as well as in the withdrawal of life support treatments; these situations have mainly confronted doctors on the front line, to face serious ethical problems; that have forced the choice of different alternatives to guarantee a greater community good, such as the prioritization of patients with the greatest probability of surviving COVID 19, selection of those who have lived fewer stages of life, who have a social utility, fewer comorbidities, among others, many of these criteria have been observed, especially age, so Ruth Macklin rejects "age or age ranges" as a decisive factor for the allocation of ventilators in the event of a criterion tie in the context of pandemics [40].

Robert et to the., In the article "Ethical Dilemmas due to the pandemic of the Covid 19" identifies ten elements to support the decision of the intensivists to admit or not a patient in the ICU, based on scores 
of fragilities, comorbidities, knowledge the patient's advance will, evaluation of the patient's previous or estimated quality of life, as well as the importance of collegiate decision-making and consultation with experts [39]. It should be noted that, in most Latin American countries, advance directives are not regulated despite the pandemic, which in this context could protect and respect the autonomy of patients affected by severe COVID-19 [41] and avoid procedures invasive not approved by the patient.

Some recommendations, guidelines and provisions have been given to support decision-making with utilitarian approaches in the allocation of ICU hospital beds in a state of catastrophe comparable to the current pandemic, however, some of these use prognostic criteria in addition to in the long term and functional status, the exclusion of groups of patients with certain serious comorbidities, this restriction would compromise the principle of justice, it is therefore necessary that all patients have the chance of being eligible.

\section{The conflict between the efforts of physicians to care for patients and the lack of a culture of self-care for the health of the population:}

It should be noted that, in the region, an attitude of self-medication [42] and of pre-hospital medication has been added in the general population, which in many cases has devastating effects such as delay in hospital care, serious adverse reactions, worsening disease, among others [43]. The health professional has a low incidence in the face of the desperate actions of the population, whether it is motivated by the lack of care given the saturation of the services, the perception of the population of dying in hospital services and the lack of specialized professionals for care, the event with the greatest weight in the population has been the scene of corpses in the streets or on the outskirts of hospitals, followed by queues of patients trying to be admitted to hospital services.

The health professional is limited to exercise his role as treating physician, in the face of the overwhelmed measures of the population seeking immediate attention. The various information media have an impact on the population's self-medication, which is why reports from professionals have tried to spread the word about the risks of using drugs with serious side effects. Professional ethics only affects this level as a guild that supports the ethical guidelines of the medical prescription and the precautionary form with which the instructions for the use of the medication must be given. Given the controversies that occurred in the region, there were governments that supported giving medication from pharmaceutical products whose scientific evidence does not exist for the treatment of patients with COVID-19.

\section{The conflict of values between the duties of the doctor to save life and the risk of life of the doctor himself:}

In this pandemic, an exacerbation of occupational risks has been observed in health personnel, with the constant threat of being infected during the execution of invasive procedures that generate aerosols to save the lives of their patients with COVID 19, it adds to this, working in environments with exposure to patients with high viral load and with difficult access to personal protective equipment [44]. Under this context, it is that many doctors around the world, complying with the Hippocratic Oath and the principle 
of beneficence, have been infected or have died victims of SARS-CoV-2 and its complications [7]. Many doctors, in addition, continue to work in COVID services, although they do not have related specialties, but due to the lack of human resources, they had to leave their usual services, to be able to work in COVID units.

\section{The conflict between the treatment plan and the unscientific information circulating on the networks and the conflict between the efforts of doctors to treat patients:}

In the context of this health emergency, the general population, health systems, governments and academics have faced uncertainty, which has brought many urgent questions, few answers and even information without scientific support, which circulates and frightens the general population. Decisionmaking based on evidence requires valid information, the product of fast and efficient processes, that comply with a neat development and deep respect for ethical principles and recommendations, scientific validity [45], compliance with national and international regulatory frameworks, scientific integrity. It is also required to encourage and finance research with social value and that the information generated is at the service of the population. Non-maleficence as part of medical practice has been forgotten as a principle that should guide the technical competence of the health professional, in the absence of scientific evidence where the practice in each context of treatment of COVID-19 patients builds daily experience for therapeutic management.

\section{Decision making to prioritize the patient health personnel in their care and life support measures in ICU).}

In this regard, PAHO also establishes "Prioritize those who have the task of saving the lives of others: People such as health providers risk their lives to save the lives of others. Prioritizing their care therefore responds to a criterion of justice, and also allows saving the greatest number of lives given their central role in caring for others" (PAHO 2020).

The prioritization of doctors for their care in critical units also implies reciprocity towards health professionals in which society rewards the professional to put themselves at risk to help patients without any discrimination and in many cases working with demand and demand that exceed their possibilities.

The health workers must receive support for priority access to COVID-19 vaccines too [46], therefore, the prioritization of health personnel is related to the instrumental value of their profession, since they are the ones who are struggling in the different services health against this fearsome disease and it is most likely that after recovering their health, they will continue in that same role.

In this regard, several questions arise, such as the perception of the discrimination community of the social value of each patient, but also doubts within the health system itself, such as: what type of doctors to prioritize? Who prioritizes? and under what criteria? In this decision-making, there could be inequity scenarios, for example: Do we owe greater reciprocity to the doctors who care for COVID patients on the first line, such as the areas of triage, ICU, trauma shock and COVID hospitalization? would they be left out 
or should prioritization be extended to physicians who support diagnosis and treatment, directly as the area of tomography, dialysis, etc.? or Should all general practitioners in the community contagion phase be included, where every patient with any pathology could also be infected with COVID? Faced with these questions, the proposal of Bianchini Alahi Dana; Rivera López, Eduardo Enrique; Luna, Florence; Alegre, Marcelo; Perez, Diana Inés and Ignacio Mastroleo, to share decisions: "this kind of decision is not only the responsibility of doctors or hospital authorities, but, ultimately, the community in general and each person interested in the particular case" [47] likewise, they conclude on the need to take the support of an approved legal framework, of specific norms on the subject [47].

Ezequiel Emanuel and team, in the article called: "Fair Allocation of Scarce Medical Resources in the Time of Covid-19" adapt ethical recommendations to COVID 19: On "the maximization of benefits" as a utilitarian value, which implies "saving the greatest number of individual lives or save patients with more years of life after treatment", Ezequiel proposes a random selection of COVID 19 patients or in order of arrival, to avoid unequal treatment between patients [48]

Due to the rapid progress of the pandemic, hospitals globally were already preparing to face difficult situations such as the imbalance between the demand for clinical care and the effective availability of ICU beds, hospitalization, among others [49]. In the present study, the interviewees also identified the dilemma related to (decision making to prioritize the patient health personnel in their care and life support measures in ICU), regarding this situation, Persad G, Wertheimer A and Emanuel E. in an article published in The Lancet called "Principles for allocation of scarce medical interventions" [15], they justified the prioritization of health personnel in a pandemic situation by assigning them an "instrumental value" by recognizing the moral importance of "those who can saving others, or rewarded those who have saved others in the past [15]. Ezequiel Emanuel emphasizes the need for a "multi-value ethical framework that can be adapted, depending on the resource and the context" [15].

\section{Conclusions And Recommendations}

The doctors and university teachers of the analyzed sample identified various situations of frequent ethical problems due to the high exposure to risks of health professionals, lack of human resources, lack of personal protective equipment, and exposure to high viral load and how ethical dilemmas frequent conflicts in the triage of patients and the availability of beds, and saving the greatest number of lives in the face of a situation of few resources in the care of COVID-19 patients.

Ethical dilemmas were analyzed from the values of profit maximization, equity, as well as ethical principles such as beneficence, social justice, distributive justice and solidarity, especially in marginalized communities.

Insufficient infrastructure conditions, low equipment capacity in ICUs, and non-specialized professionals to deal with the management of COVID-19 patients are a characteristic of health systems pre-existing to the pandemic, as well as conditions of limited access to health in marginalized communities, the risk 
being that these situations of injustice persist or worsen after the pandemic due to the worsening of the social and financial situation [50].

In this scenario, university doctors and teachers are facing adversities under which they must make dilemmatic decisions contrasting moral values to protect health against a pandemic that is undermining the economic and social balance of the region. The ethical recommendation guides have the possibility of building a framework for reflection to guide the decision-making that the treating physician must inevitably make in the face of COVID-19 patients and future pandemics.

\section{Abbrevations}

CIEl Institutional Research Ethics Committee

COVID-19: Coronavirus Disease 2019

IBM SPSS: Statistical Package for the Social Sciences

ICU: Intensive Care Unit

ICUs: Intensive Care Units

PPE: Personal protective equipment

PAHO: Pan American Health Organization

SARS-CoV-2: Severe acute respiratory syndrome coronavirus 2

UNESCO: Universal Declaration of Bioethics and Human Rights

WHO: World Health Organization

\section{Declarations}

\section{Ethics Declarations}

Ethics approval and consent to participate

The study was approved by the Institutional Research Ethics Committee of the Universidad Católica de Santa María, reference number CIEI (193-2020), it also complies with the ethical principles of the Declaration of Helsinki, the sensitive data of the participants has been protected.

Consent for publication

This study has consent for the publication of results. 
Availability of data and materials

The datasets analyzed during the current study available from the corresponding author on reasonable request.

\section{Competing interests}

The authors declare that they have no competing interests.

\section{Funding}

This study was conducted with Self-financed. The authors declare that they have no competing interests.

\section{Authors' contributions}

AMCT, EV, LBMC: conceptualization and execution of the research project. AMCT, EV, FT, LLD and LBMC performed the data collection and data analysis. AMCT, EV, FT, LMLD interpreted the data. AMCT, EV, FT, LMLD, LBMC and EMC drafted the manuscript. All authors read and approved the final manuscript.

\section{Acknowledgements}

A thank you to each of the Peruvian physicians and local and international bioethics professors, who accepted the completion of the questionnaire, a very special thanks to the Interdisciplinary Seminary of Bioethics Mexico, for their great support.

\section{References}

1. Huang C, Wang Y, Li X, Ren L, Zhao J, Hu Y, et al. Clinical features of patients infected with 2019 novel coronavirus in Wuhan, China. Lancet. 2020; 395(10223):497-506

2. World Health Organization. WHO Director-General's remarks at the media briefing on 2019-nCoV on February 11, 2020. https://www.who.int/dg/speeches/detail/who-director-general-s-remarks-at-the-mediabriefingon-2019-ncov-on-11-february-2020. Published February 11, 2020

3. OMS, Alocución de apertura del Director General de la OMS en la rueda de prensa sobre la COVID-19 celebrada el 11 de marzo de 2020, (n.d.). (Accessed January November 2, 2020)

https://www.who.int/es/dg/speeches/detail/who-director-general-sopening-remarks-at-the-mediabriefing-on-covid-19-11-march-2020

4. COVID-19 Dashboard by the Center for Systems Science and Engineering (CSSE) at Johns Hopkins University. (Accessed January 3, 2021):https://coronavirus.jhu.edu/map.html

5. Maguiña Vargas Ciro. Reflections on COVID-19 infection, Colegio Medico del Peru and the Public Health. Acta méd. Peru. 2020; 37(1): 8-10 http://dx.doi.org/10.35663/amp.2020.371.929. 
6. Donat Laporta, Emilio; Andreu Tena, Eduardo; Baladía Olmedo, Carmen. Afectación de la pandemia por Covid-19 en los servicios médico forenses de Madrid (España). Rev. esp. med. Legal. 2020;153-158.

7. Galán-Rodas, Edén; Tarazona-Fernández, Augusto; Palacios-Celi, Miguel. Riesgo y muerte de los médicos a 100 días del estado de emergencia por el COVID-19 en Perú. Acta Médica Peruana. 2020;37(2): 119-121.

8. World Health Organization. Critical preparedness, readiness and response actions for COVID-19. Geneva: WHO, 2020.

9. Rosenbaum SJ, Bayer R, Bernheim RG, et al. Ethical considerations for decision making regarding allocation of mechanical ventilators during a severe influenza pandemic or other public health emergency. Atlanta: Centers for Disease Control and Prevention, 2011 (https://www.cdc.gov/od/science/integrity/phethics/docs/Vent_Document_Final_Version.pdf. opens in new tab).

10. Zucker H, Adler K, Berens D, et al. Ventilator allocation guidelines. Albany: New York State Department of Health Task Force on Life and the Law, November 2015

(https://www.health.ny.gov/regulations/task_force/reports_publications/docs/ventilator_guidelines.pdf. opens in new tab).

11. To, Kelvin Kai-Wang, et al. COVID-19 re-infection by a phylogenetically distinct SARS-coronavirus-2 strain confirmed by whole genome sequencing. Clinical Infectious Diseases, 2020.

12. Aleta, Alberto, et al. Modelling the impact of testing, contact tracing and household quarantine on second waves of COVID-19. Nature Human Behaviour. 2020; 4 (9): 964-971.

13. Galicia, Carlos Manuel Guerra. Análisis de dilemas éticos clínicos. Bioética, derecho y derechos humanos, p. 65.

14. Torabi, Mohammad, et al. Experiences of pre-hospital emergency medical personnel in ethical decision-making: a qualitative study. BMC medical Ethics. 2018; 19 (1): 95.

15. Persad G, Wertheimer A, Emanuel EJ. Principles for allocation of scarce medical interventions. Lancet. 2009; 373:423-431.

16. Tang, Song, et al. Aerosol transmission of SARS-CoV-2? Evidence, prevention and control. Environment international. 2020; 144: 106039

17. Andreau de Bennato, M. "Consideraciones sobre algunos aspectos de la Bioética y su relación con las formas de argumentación moral”. en F. J. León Correa y P. Sorokin (coords.) Bioética y Salud Pública en y para América Latina. FELAIBE. [en línea]. http://www.bioeticachile.cl/felaibe/documentos/Bioetica_y_Salud_Publica_LA.pdf 
18. Prateek Bahl, Con Doolan, Charitha de Silva, Abrar Ahmad Chughtai, Lydia Bourouiba, C Raina Maclntyre, Airborne or Droplet Precautions for Health Workers Treating Coronavirus Disease 2019 ?, The Journal of Infectious Diseases jiaa189, https://doi.org /10.1093/infdis/jiaa189

19. Heinzerling, Amy, et al. Transmission of COVID-19 to health care personnel during exposures to a hospitalized patient-Solano County, California, February 2020. 2020.

20. Cabrini, Luca; Landoni, Giovanni; Zangrillo, Alberto. Minimize nosocomial spread of 2019-nCoV when treating acute respiratory failure. The Lancet. 2020; 395 (10225): 685.

21. Bauchner, Howard; Fontanarosa, Phil B.; Livingston, Edward H. Conserving supply of personal protective equipment-a call for ideas. Jama. 2020; 323 (19): 1911-1911.

22. Ing, E. B., et al. Physician deaths from corona virus (COVID-19) disease. Occupational Medicine. 2020; 70 (5): $370-374$.

23. Muñoz del Carpio-Toia, Agueda et all. Violencia laboral contra médicos del Servicio de Salud de Atención Primaria. Arequipa, Perú. Opción, Año 35, Regular. 2019; 90: 18-40 https://produccioncientificaluz.org/index.php/opcion/article/view/30457

24. Wang, Wei, et al. Mental health problems in Chinese healthcare workers exposed to workplace violence during the CoViD-19 outbreak: a cross-sectional study using propensity score matching analysis. Risk management and healthcare policy. 2020; 13: 2827-2833.

25. Bedoya JCM. COVID-19: the pandemic of abuse against health personnel in times of pandemic. IJEPH. 2020; 3(1): e-6276

26. Huarcaya-Victoria, Jeff. Consideraciones sobre la salud mental en la pandemia de COVID-19. Revista Peruana de Medicina Experimental y Salud Pública. 2020;37(2):327-34

27. Arias Gallegos, Walter Lizandro; Síndrome de burnout en personal de enfermería de Arequipa. Revista Cubana de Salud Pública. 2016; 42: 559-575.

28. Muñoz-del-Carpio Toya, Agueda; Arias Gallegos, Walter L.; Caycho-Rodríguez, Tomás. Síndrome de burnout en médicos de la ciudad de Arequipa (Perú). Revista chilena de neuro-psiquiatría. 2019; 57 (2): 139-148.

29. Mattila, Elina, et al. COVID-19: anxiety among hospital staff and associated factors. Annals of Medicine, 2021, vol. 53, no 1, p. 237-246.

30. Spoorthy, Mamidipalli Sai; Pratapa, Sree Karthik; Mahant, Supriya. Mental health problems faced by healthcare workers due to the COVID-19 pandemic-A review. Asian journal of psychiatry. 2020; 51: 102119. 
31. Withers M, Dawson A, Caicedo A, Ho CW, Guillemot J, de Jesus Medina-Arellano M, de Castro L. Inequities, vulnerabilities and ethics in the time of COVID-19: diverse perspectives from the APRU Global Health Program. J Glob Health Sci. 2020;2(2): e25

32. El-Khatib, Ziad, et al. The disproportionate effect of COVID-19 mortality on ethnic minorities: Genetics or health inequalities? EClinicalMedicine. 2020; 23.

33. Flood, Colleen M.; Macdonnell, Vanessa; Philpott, Jane. Vulnerable: The Law, Policy and Ethics of COVID-19. 2020.

34. Sorokin, Patricia, et al. Datos en tiempos de pandemia: la urgencia de un nuevo pacto. Reflexiones desde América Latina y el Caribe. Revista de Bioética y Derech. 2020; 50: 221-237. https://revistes.ub.edu/index.php/RBD/article/view/31832

35. Smith, Maxwell J., et al. Ethical conditions for accelerating COVID-19 vaccine research. Wellcome Open Research. 2020; 5(249): 249.

36. UNESCO. Universal Declaration of Bioethics and Human Rights 2005.

http://portal.unesco.org/es/ev.php-URL_ID=31058\&URL_DO=DO_TOPIC\&URL_SECTION=201.html

37. Maves, Ryan C., et al. Triage of scarce critical care resources in COVID-19: an implementation guide for regional allocation An expert panel report of the Task Force for Mass Critical Care and the American College of Chest Physicians. Chest, 2020.

38. Pan American Health Organization. Ethical Guidance for the Use of Limited Resources in Critical Health Services During the COVID-19 Pandemic.

https://iris.paho.org/bitstream/handle/10665.2/52092/OPSHSSBIOCOVID19200012_spa.pdf? sequence $=1$ \&isAllowed $=y$

39. Robert, René, et al. Ethical dilemmas due to the Covid-19 pandemic. Annals of intensive care. 2020; 10 (1): 1-9.

40. Macklin R. Allocating medical resources fairly: the CSG bioethics guide. Salud Publica Mex: 2020;62(5):590-2. https://www.saludpublica.mx/index.php/spm/article/view/11486

41. Poveda-Moral, Silvia; Bosch-Alcaraz, Alejandro; Falcó-Pegueroles, Anna. La planificación de decisiones anticipadas como estrategia preventiva de conflictos éticos en urgencias y emergencias durante y después de la COVID-19. Revista de Bioética y Derecho. 2020; 50: 189-203.

42. Nasir, Morshed; Salauddin Chowdhury, A. S. M.; Zahan, Tahmina. Self-medication during COVID-19 outbreak: a cross sectional online survey in Dhaka city. Int J Basic Clin Pharmacol. 2020; 9 (9):1325-30.

43. Mallhi, Tauqeer Hussain, et al. Drug repurposing for COVID-19: a potential threat of self-medication and controlling measures. Postgraduate medical journal, 2020. 
44. Liu Min, Cheng Shou-Zhen, Xu Ke-Wei, Yang Yang, Zhu Qing-Tang, Zhang Hui et al. Use of personal protective equipment against coronavirus disease 2019 by healthcare professionals in Wuhan, China: cross sectional study BMJ. 2020; 369:m2195.

45. Kwon D. How swamped preprint servers are blocking bad coronavirus research. Nature. 2020;581(7807):130-131

46. Persad, Govind; Peek, Monica E.; Emanuel, Ezekiel J. Fairly prioritizing groups for access to COVID-19 vaccines. Jama. 2020; 324 (16): 1601-1602.

47. Bianchini, Alahi Dana; Rivera López, Eduardo Enrique; Luna, Florencia; Alegre, Marcelo; Perez, Diana Ines; et al.; Algunas cuestiones éticas a propósito de la pandemia de Covid-19; Asociación Civil Ciencia Hoy; Ciencia Hoy. 2020; 29 (170): 15-19

48. Emanuel, Ezekiel J., et al. Fair allocation of scarce medical resources in the time of Covid-19. 2020. N Engl J Med. 2020; 382(21):2049-2055.

49. Vergano, Marco, et al. Clinical ethics recommendations for the allocation of intensive care treatments in exceptional, resource-limited circumstances: the Italian perspective during the COVID-19 epidemic. Critical Care. 2020; 24(1):165

50. Garrett, Jeremy R., et al. Our Next Pandemic Ethics Challenge? Allocating "Normal" Health Care Services. Hastings Center Report. 2020; 50(3): 79-80

\section{Tables}

Table 1. Contact with COVID-19 patients 


\begin{tabular}{|lll|}
\hline & $\mathbf{n}$ & $\%$ \\
\hline Participants & 100 & \\
\hline Contact with COVID patients & & \\
\hline No & 27 & 27.0 \\
\hline Yes & 73 & 73.0 \\
\hline Contact time with COVID patients & & \\
\hline 1 month & 1 & 1.4 \\
\hline 2 months & 9 & 12.3 \\
\hline 3 months & 7 & 9.6 \\
\hline 4 months & 15 & 20.5 \\
\hline 5 months & 29 & 39.7 \\
\hline 6 months & 12 & 16.4 \\
\hline Workplace & & \\
\hline Intensive care unit & 6 & 6.0 \\
\hline Emergency - trauma shock & 33 & 33.0 \\
\hline Medicine hospitalization & 16 & 16.0 \\
\hline Triage & 12 & 12.0 \\
\hline Clinic & 11 & 11.0 \\
\hline University teaching / bioethics & 22 & 22.0 \\
\hline
\end{tabular}

Table 2. Situations that occur in the health system 


\begin{tabular}{|lll|}
\hline Situations that arise in the health system & $\mathbf{n}$ & $\%$ \\
\hline Participants & 100 & 100 \\
\hline Exposure to risks of health professionals & & \\
\hline High exposure to risks of health professionals & 63 & 9.3 \\
\hline Exposure to high viral load & 68 & 6.8 \\
\hline Discrimination and mistreatment of doctors & 56 & 5.6 \\
\hline Fear of getting infected & 25 & 2.5 \\
\hline Deficiencies and gaps in the health system & & \\
\hline Human resource deficiencies & 85 & 8.5 \\
\hline Infrastructure gap, ICU beds and hospital beds & 43 & 4.3 \\
\hline Lack of medicines, ventilators and medical equipment & 48 & 4.8 \\
\hline Little Research & & \\
\hline Little national investigation on COVID-19 & 51 & 5.1 \\
\hline Dissemination of therapies not yet proven with clinical trials & 13 & 1.3 \\
\hline Difficult access to Molecular tests and research on the subject & 22 & 4.9 \\
\hline Poor public health and lack of self-care of the population & & \\
\hline Little support for public health and little primary health care & 30 & 3.0 \\
\hline Self-medication of the population & 19 & 1.9 \\
\hline Patients attend health services in advanced stages & 17 & 1.7 \\
\hline Others & 66 & 6.6 \\
\hline
\end{tabular}

Table 3. Conflicts and ethical dilemmas that occur in times of pandemic... 


\begin{tabular}{|c|c|c|c|}
\hline Conflicts and Ethical Dilemmas in the COVID 19 Pandemic & $\begin{array}{l}\text { Very } \\
\text { frequent } \\
\text { / } \\
\text { Frequent }\end{array}$ & Occasional & $\begin{array}{l}\text { Rare } \\
\text { 'Never }\end{array}$ \\
\hline \multicolumn{4}{|l|}{ Decision making to allocate resources } \\
\hline $\begin{array}{l}\text { Conflicts in the allocation of ventilators and the availability of } \\
\text { beds and the demand for critical patients }\end{array}$ & 76 & 9 & 15 \\
\hline \multicolumn{4}{|l|}{$\begin{array}{l}\text { The conflict between the efforts of physicians and the lack of } \\
\text { culture of self-care for the health of the population }\end{array}$} \\
\hline $\begin{array}{l}\text { Conflict between medical effort and lack of self-care of the } \\
\text { population, non-compliance of the population with isolation } \\
\text { measures, hygiene measures and lack of use of masks }\end{array}$ & 70 & 15 & 15 \\
\hline \multicolumn{4}{|l|}{$\begin{array}{l}\text { The conflict of values between the duties of the doctor } \\
\text { to save the life and risk of life of the doctor himself }\end{array}$} \\
\hline $\begin{array}{l}\text { Conflict of values between the doctor's duties to save life and the } \\
\text { risk to the life of the doctor himself due to lack of adequate } \\
\text { personal protective equipment and work environment conditions }\end{array}$ & 67 & 17 & 16 \\
\hline \multicolumn{4}{|l|}{$\begin{array}{l}\text { The conflict between the treatment plan and the information } \\
\text { without scientific support and without clinical trials }\end{array}$} \\
\hline $\begin{array}{l}\text { Conflict between the treatment plan and unscientific information } \\
\text { circulating on the networks, lack of therapies or procedures not } \\
\text { yet proven with clinical trials }\end{array}$ & 64 & 26 & 10 \\
\hline \multicolumn{4}{|l|}{ Decision making to prioritize the patient health personnel } \\
\hline $\begin{array}{l}\text { Decision making to prioritize the patient health personnel in their } \\
\text { care and life support measures in ICU }\end{array}$ & 61 & 22 & 17 \\
\hline
\end{tabular}

